\title{
Endovascular Thrombectomy in Wake-Up Stroke and Stroke with Unknown Symptom Onset
}

\author{
(D) P. Bücke, (D) M. Aguilar Pérez, DV. Hellstern, (D) M. AlMatter, ${ }^{D}$ H. Bäzner, and $\mathbb{D}_{\text {H. Henkes }}$
}

\begin{abstract}
BACKGROUND AND PURPOSE: Mechanical thrombectomy in acute ischemic stroke within 6 hours of symptom onset is effective and safe. However, in many patients, information on the beginning of symptoms is not available. Patients can be divided into those with wake-up stroke and daytime-unwitnessed stroke. Evidence on outcome and complications after mechanical thrombectomy in wake-up stroke and daytime-unwitnessed stroke is rare. A potential beneficial effect of mechanical thrombectomy in selected patients with wake-up stroke or daytime-unwitnessed stroke is suspected.
\end{abstract}

MATERIALS AND METHODS: We analyzed 1073 patients with anterior circulation stroke undergoing mechanical thrombectomy between 2010 and 2016. Patients with wake-up stroke and daytime-unwitnessed stroke were compared with controls receiving mechanical thrombectomy as the standard of care. We assessed good functional outcome (mRS $\leq 2$ at 3 months), mortality rates, and frequencies of symptomatic intracranial hemorrhage. Subgroup analyses tried to detect influences of patient selection via further imaging modalities (MR imaging, CTP; wake-up stroke [advanced], daytime-unwitnessed stroke [advanced]) on outcome and safety.

RESULTS: There was no significant difference in good functional outcome between patients with wake-up stroke and controls (35.9\% versus $38.3 \%, P=.625)$. Outcome in patients with daytime-unwitnessed stroke was inferior compared with controls (27.3\%, $P=.007)$. Groups did not differ in all-cause mortality at day $90(P=.224)$ and the rate of symptomatic intracranial hemorrhage $(P=.292)$. Advanced imaging improved the frequency of good functional outcome (non-wake-up stroke [advanced] versus wake-up stroke [advanced]: OR, 2.92; 95\% CI, 1.32-6.45; nondaytime-unwitnessed stroke [advanced] versus daytime-unwitnessed stroke [advanced]: OR, 2.09; 95\% Cl, 1.03-4.25) with an additional reduction in all-cause mortality (non-daytime-unwitnessed stroke [advanced] versus daytime-unwitnessed stroke [advanced]: OR, 0.42; 95\% Cl, 0.20-0.88).

CONCLUSIONS: Mechanical thrombectomy in selected patients with wake-up stroke allows a good functional outcome comparable with that of controls. Outcome after mechanical thrombectomy in daytime-unwitnessed stroke seems to be inferior compared with that in controls. Advanced imaging modalities may increase the frequency of good functional outcome in both patients with wake-up stroke and daytime-unwitnessed stroke.

ABBREVIATIONS: aTE = aspiration thrombectomy; DUS = daytime-unwitnessed stroke; $\mathrm{mTE}=$ mechanical thrombectomy; WUS = wake-up stroke

M echanical thrombectomy (mTE) in acute ischemic stroke due to embolic large-vessel occlusion has been shown to be effective and safe. Several randomized controlled trials have demonstrated the superiority of mTE in combination with intrave-

Received August 21, 2017; accepted after revision November 13.

From the Psychiatric University Hospital Zurich (P.B.), University of Zurich, Zurich, Switzerland; Neurological Clinic (P.B., H.B.) and Neuroradiological Clinic (M.A.P., V.H., M.A., H.H.), Klinikum Stuttgart, Stuttgart, Germany; and Medical Faculty (H.H.), University Duisburg-Essen, Essen, Germany.

Please address correspondence to Philipp Bücke, MD, Neurological Clinic, Klinikum Stuttgart, Kriegsbergstr 60-62, 70174 Stuttgart, Germany;

e-mail: philipp.buecke@gmail.com

$\equiv$ Indicates article with supplemental on-line tables.

Indicates article with supplemental on-line photos.

http://dx.doi.org/10.3174/ajnr.A5540 nous thrombolysis compared with intravenous thrombolysis alone. ${ }^{1-5}$ Subsequently, specific recommendations for patient selection and execution of mTE and/or aspiration thrombectomy (aTE) were implemented (eg, initiation within 6 hours after symptom onset). ${ }^{6}$ However, in many patients, information on the beginning of stroke symptoms is not available. They might therefore be excluded from beneficial endovascular therapy. Evidence on mTE in a prolonged time window is inconsistent, and data on the efficacy and safety of mTE in patients with unknown symptom onset are rare. ${ }^{7-9}$

\section{MATERIALS AND METHODS}

From our ongoing prospective single-center stroke registry, consecutive patients treated with mTE/aTE between January 2010 and December 2016 were considered for this retrospective non- 
interventional analysis. Patients were either primarily treated in our center (Neurozentrum, Klinikum Stuttgart) or secondarily transferred from hospitals in surrounding cities. ${ }^{10}$ Nonetheless, enrollment was based on the initial intention to treat patients via mTE/aTE. There was no secondary triage, selection procedure, or additional imaging before the intervention. The study was approved by the local institutional review board.

\section{Study Population}

Patients with an anterior circulation stroke due to an occlusion of the ICA, the intracranial carotid bifurcation, or an M1 or M2 branch of the MCA were included. Patients with an occlusion of an MCA M3 branch, the anterior cerebral artery, or the posterior circulation were excluded. In case of an initial proximal vessel occlusion that was later found recanalized during angiography (spontaneously or after intravenous thrombolysis), datasets were removed from further analysis. We did exclude patients who were not treated according to current recommendations (eg, because of a delayed treatment onset) unless they were classified as having wake-up stroke (WUS) or daytime-unwitnessed stroke (DUS). ${ }^{6}$ Further exclusion criteria were the following: stent angioplasty without mTE/aTE due to high-grade intra- or extracranial stenosis or dissection because of anticipated differences in clinical outcome; the application of older generation stent retrievers and aspiration systems not used in recent randomized controlled trials (the following stent retrievers and aspiration systems were included: Solitaire FR, Medtronic, Minneapolis, Minnesota; pREset, phenox, Bochum, Germany; ACE aspiration catheters, Penumbra, Alameda, California; and Sofia, MicroVention, Tustin, California); and the lack of a 3-month follow-up. Datasets with inconsistent information that could not be verified were excluded.

Patients treated within 6 hours of symptom onset (according to current guidelines) were included in the control group (C). Because of expected differences in pathophysiology and outcome, patients with an unknown symptom onset were divided in the following manner: 1) WUS, occurring out of sleep in the early morning hours; 2) DUS. ${ }^{11-13}$ WUS was defined as stroke symptoms being present during awakening. Patients had to be asymptomatic when going to sleep and during the night. DUS included patients who were asymptomatic while waking up or had recognized symptoms at some point during day or night. Patients without information on "last seen well" who could not be specified as having WUS by the assessing neurologist were subsumed in DUS.

Subgroup analyses were conducted using consecutive steps in patient selection: 1) further imaging modalities with CTP or MR imaging allowing patient selection due to a mismatch concept (CBV versus TTP or MTT in CTP, FLAIR-DWI mismatch in MR imaging; WUS[advanced], DUS[advanced]); and 2) advanced imaging with MR imaging only (WUS [mri], DUS [mri]). ${ }^{14-19}$ Examples of mismatch in both MR imaging and CTP are shown in On-line Figs 1-3. The decision to perform advanced imaging was made by the respective stroke specialist. In patients without CTP or MR imaging, we routinely opted for mTE when there was a proved vessel occlusion (eg, in CTA, hyperdense vessel sign), no major demarcation of infarcted tissue on plain CT, or an ASPECTS score of $\geq 4$. There was no fixed CTP protocol (eg, quantitative measurement or thresholds defining mismatch). Information on a possible mismatch was reported by the referring hospital or our neuroradiology department. The results were validated by the neurointerventionalist before endovascular therapy. WUS[mri] and DUS[mri] were subsequently compared with a selected control group (C[mri]) with MR imaging as the initial imaging technique. To detect a possible effect of imaging selection on outcome, we compared patients with WUS and DUS in subgroups 1 and 2 with the remaining patients with WUS or DUS not part of the respective group (eg, WUS[mri] versus non-WUS[mri]).

\section{Outcome Measures}

Primary outcome measure was mRS at day 90, with mRS 0-2 indicating good functional outcome. Secondary outcome measures were the following: 1 ) development of a symptomatic intracranial hemorrhage according to the Solitaire with the Intention for Thrombectomy as Primary Endovascular Treatment for Acute Ischemic Stroke (SWIFT PRIME) criteria (parenchymal hemorrhage type 1 or 2, SAH, or intraventricular hemorrhage within 24 hours after mTE with a deterioration in the NIHSS score of $\geq 4$ points or leading to death $)^{20}$;2) in-hospital mortality; and 3) allcause mortality at day 90 .

\section{Data Collection}

Information on age, sex, medical history, stroke onset, NIHSS, imaging technique, mRS score, and stroke etiology was drawn from referral letters, admission notes, or discharge papers. Imaging times were stored in our PACS. Periprocedural information (eg, TICI scores) was documented by the neuroradiology department. Follow-up data were collected by our study nurse via telephone calls.

\section{Statistical Analysis}

Numeric baseline characteristics were described in medians (quartiles) or means (SDs). Categoric baseline parameters were described in frequencies. For comparing groups, the Fisher exact test or the $\chi^{2}$ test was used for categoric parameters. Numeric parameters were analyzed with the Kruskal-Wallis-test or the Mann-Whitney $U$ test as appropriate. Dichotomized outcome (head-to-head comparison of groups) was evaluated in a univariate logistic regression model adjusting for possible confounders (based on literature research; baseline-NIHSS, age, ICA occlusion, stroke etiology, imaging-to-groin time, diabetes mellitus, and hypertension). A $P$ value $<.05$ was considered statistically significant. STATA/IC 13.1 for Windows (StataCorp, College Station, Texas) was used for statistical analysis.

\section{RESULTS}

Between January 2010 and December 2016, one thousand nine hundred sixty-one patients were treated with mTE/aTE, 888 patients $(45.2 \%)$ did not meet the predefined inclusion criteria (Fig 1 ), and 1073 patients (54.8\%) would eventually be analyzed. Most $(n=780,72.7 \%)$ formed the control group. In 293 patients (27.3\%), symptom onset was unclear. One hundred twenty-eight patients (11.9\%) were categorized as having WUS; and 165 (15.4\%), DUS.

AJNR Am J Neuroradiol 39:494-99 Mar 2018 www.ajnr.org 
The baseline characteristics are shown in On-line Table 1. There was no difference in the frequency of good functional outcome ( $\mathrm{mRS} \leq 2)$ between patients with WUS and controls $(35.9 \%$ versus $38.3 \%, P=.625$; Table 1 ). Good functional outcome was reduced in those with DUS compared with controls $(27.3 \%, P=$ $.007)$. WUS and DUS did not differ significantly $(P=.127)$. Figure 2 illustrates the distribution of mRS scores at day 90 . In-hospital mortality (C: $18.9 \%$; WUS: $12.6 \%$; DUS: $23.3 \%$; $P=.067$ ) and all-cause mortality at day 90 (C: $26.5 \%$; WUS: $22.7 \%$; DUS: $31.5 \% ; P=.224)$ did not differ significantly. The rate of symp-

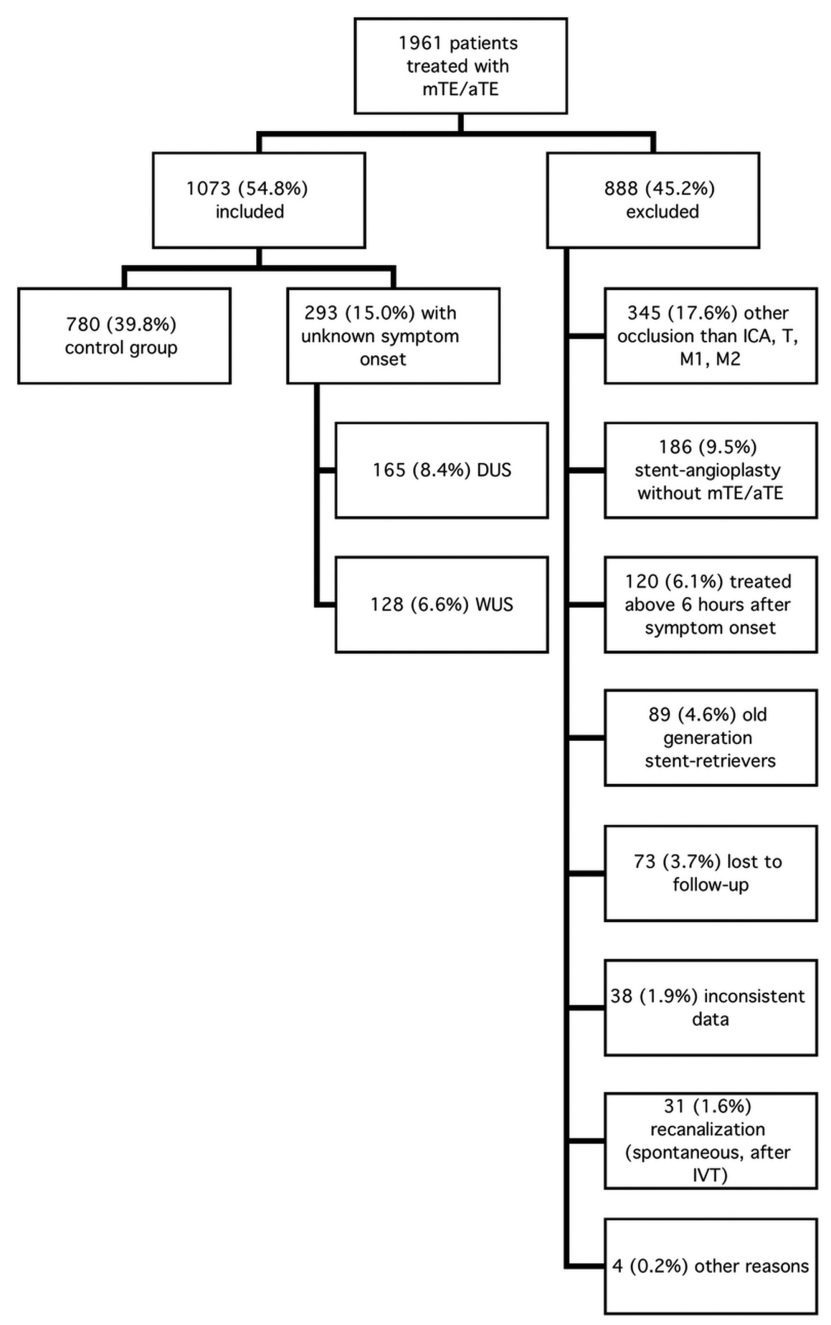

FIG 1. Flowchart depicting patient selection according to predefined inclusion and exclusion criteria. IVT indicates intravenous thrombolysis.

Table 1: Primary and secondary outcome parameters

\begin{tabular}{lccccc}
\hline & $\begin{array}{c}\text { Control Group } \\
(\boldsymbol{n}=780)\end{array}$ & $\begin{array}{c}\text { WUS } \\
(\boldsymbol{n}=128)\end{array}$ & $\begin{array}{c}\text { DUS } \\
(\boldsymbol{n}=165)\end{array}$ & $\boldsymbol{P}$ Value $^{\mathrm{a}}$ & $\boldsymbol{P}$ Value \\
\hline mRS 0-2 at 3 mo (No.) (\%) & $299(38.3)$ & $46(35.9)$ & $45(27.3)$ & .025 & (A) 625 \\
& & & & & $($ B) .007 \\
& & & & & (C). 127 \\
In-hospital mortality (No.) (\%) & $145(18.9)$ & $16(12.6)$ & $38(23.3)$ & .067 & NA \\
All-cause mortality at 3 mo (No.) (\%) & $207(26.5)$ & $29(22.7)$ & $52(31.5)$ & .224 & NA \\
sICH (No.) (\%) & $42(5.5)$ & $3(2.4)$ & $10(6.3)$ & .292 & NA \\
\hline
\end{tabular}

Note:- $\mathrm{s} \mid \mathrm{CH}$ indicates symptomatic intracranial hemorrhage.

a $P$ value for group comparison.

${ }^{b} P$ value for head-to-head comparison, calculated when the $P$ value for the group comparison was <.05: (A), control group vs WUS; (B), control group vs DUS; (C), WUS vs DUS. tomatic intracranial hemorrhage was similar in all groups $(P=$ .292, Table 1). Results did not change in the head-to-head comparison of groups adjusted for the abovementioned confounders (good functional outcome; WUS versus C: OR, 0.74; 95\% CI, $0.48-1.16 ; P=.193$; DUS versus C: OR, 0.49; 95\% CI, 0.31-0.79; $P=.003$; data not shown).

Sixty-eight of the 128 patients with WUS (53.1\%) underwent CTP or MR imaging (DUS: $n=63 ; 38.2 \%$ ). MR imaging was performed in $36.7 \%$ of patients with WUS $(n=47)$ and in $31.5 \%$ of those with DUS $(n=52)$. In WUS[advanced], mismatch was present in 52 patients $(76.5 \%$; DUS [advanced] : $n=$ 46, 73.0\%; WUS[mri]: $n=36,76.6 \%$; DUS[mri]: $n=37$, $71.2 \%)$. Subgroup analyses based on imaging selection are summarized in Table 2. When we compared WUS[advanced] and DUS[advanced] with unselected controls, there was no statistically significant difference in good functional outcome (C: 38.3\%; WUS[advanced]: 47.1\%; DUS[advanced]: $36.5 \%$; $P=.344)$. In-house mortality was reduced significantly in WUS[advanced] compared with controls (7.5\% versus $18.9 \%$, $P=.019)$. Similar results were seen in patients with WUS [mri] and DUS[mri] (Table 2).

When we compared controls with patients in the WUS and DUS subgroups presenting with a verified mismatch only, the results did not change. Mortality rates remained stable with a nonsignificant increase in the percentage of good functional outcome (WUS[advanced]: 51.9\%; DUS[advanced]: 39.1\%; WUS[mri]: 52.8\%; DUS[mri]: 43.2\%; On-line Table 2). There was no significant difference in good functional outcome among WUS[mri] (51.1\%), DUS[mri] (38.5\%), and C[mri] (48.8\%; $P=.357$; Table 2). The same was true for all-cause mortality at 3 months (C[mri]: $20.0 \%$; WUS[mri]: $12.8 \%$; DUS[mri]: $23.1 \% ; P=.385)$ and the rate of symptomatic intracranial hemorrhage $(P=.875)$.

We did compare WUS[advanced] and WUS[mri] with WUS not part of the respective groups (non-WUS[advanced], non-WUS[mri]; Table 3). Non-WUS[advanced] versus WUS [advanced] showed an increase in the rate of good functional outcome (23.3\% versus $47.1 \%$; OR, 2.92; 95\% CI, 1.32-6.45; $P=$ .006). In non-WUS[mri] versus WUS[mri], good functional outcome increased similarly (27.2\% versus $51.1 \%$; OR, 2.80; $95 \%$ CI, $1.28-6.10 ; P=.008)$ with an additional decrease in in-hospital mortality (17.3\% versus $4.3 \%$; OR, 0.22 ; 95\% CI, 0.05-1.04; $P=$ $.049)$ and all-cause mortality at day 90 (28.4\% versus $12.8 \%$; OR, 0.37 ; 95\% CI, $0.14-1.01 ; P=.05)$. For DUS, advanced imaging provided a significant improvement in the frequency of good functional outcome (non-DUS[advanced] versus DUS[advanced]: $21.6 \%$ versus $36.5 \%$; OR, 2.09; 95\% CI, 1.03-4.24; $P=.048$; non-DUS[mri] versus DUS[mri]: $22.1 \%$ versus $38.5 \%$; OR, $2.20 ; 95 \%$ CI, $1.06-4.55 ; P=.038)$. A significant reduction of in-hospital mortality (30.0\% versus $12.7 \%$; OR, $0.34 ; 95 \% \mathrm{CI}$, $0.14-0.82 ; P=.013$ ) and all-cause mortality at day $90(38.2 \%$ versus $20.6 \%$; OR, 0.42 ; 95\% CI, $0.20-0.88 ; P=.025$ ) was seen in non-DUS[advanced] versus DUS[advanced]. 


\section{DISCUSSION}

Stroke with an unknown symptom onset is frequent and accounts for up to $30 \%$ of ischemic stroke cases. ${ }^{11-13}$ WUS (in which symptoms are realized during awakening) and DUS (unrealized symptom onset during daytime) can be distinguished. Endovascular therapy is currently not approved in those patients. ${ }^{6}$ On the basis of a considerable real-world dataset, we tried to detect differences in outcome among patients with WUS, DUS, and controls (excluding patients with known symptom onset presenting $>6$ hours after notification of symptoms). In our cohort, outcome in WUS did not differ from that in controls (mRS 0-2: 35.9\% versus 38.3\%), suggesting a beneficial effect of mTE in WUS. No increase in mortality rates or the frequency of symptomatic intracranial hemorrhage was observed. Functional outcome in DUS overall was significantly inferior compared with that of controls (mRS 0-2: 27.3\%).

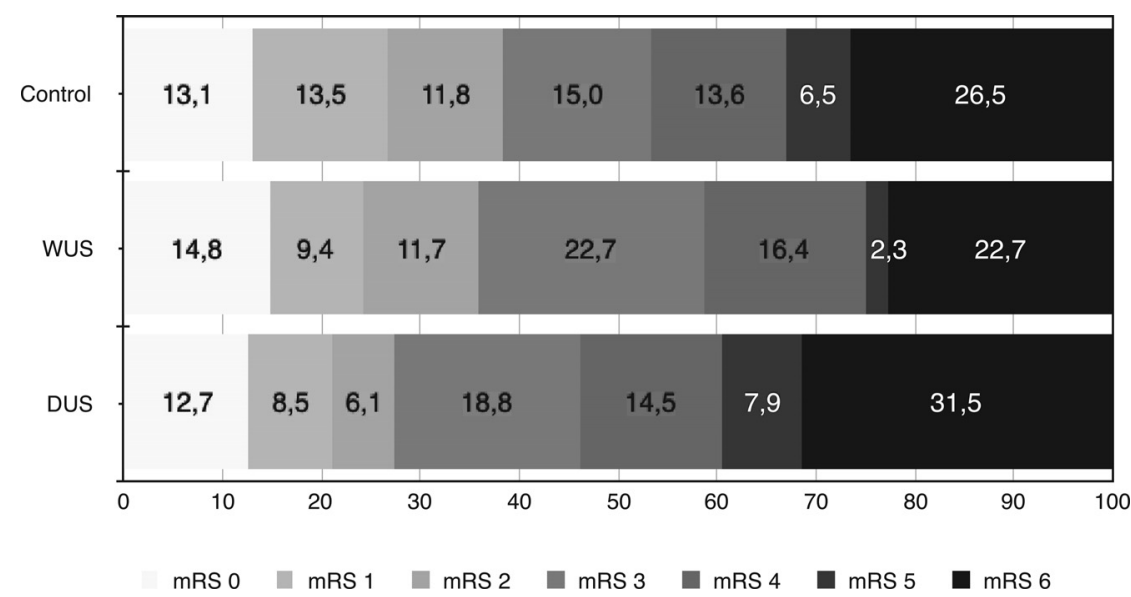

FIG 2. Distribution of mRS scores at 90 days.

Table 2: Subgroup analysis-patient selection via imaging modalities

\begin{tabular}{|c|c|c|c|c|c|}
\hline & $\begin{array}{l}\text { Control Group } \\
(n=780)\end{array}$ & $\begin{array}{c}\text { WUS[advanced] } \\
(n=68)\end{array}$ & $\begin{array}{l}\text { DUS[advanced] } \\
(n=63)\end{array}$ & $P$ Value ${ }^{a}$ & $P$ Value $^{\mathrm{b}}$ \\
\hline \multicolumn{6}{|l|}{ A) CTP or MRI [advanced] } \\
\hline mRS 0-2 (3 mo) (No.) (\%) & $299(38.3)$ & $32(47.1)$ & $23(36.5)$ & .344 & NA \\
\hline In-hospital mortality (No.) (\%) & $145(18.9)$ & $5(7.5)$ & $8(12.7)$ & .031 & $\begin{array}{l}\text { (A) } 0.019 \\
\text { (B) } .309 \\
\text { (C) } .388\end{array}$ \\
\hline All-cause mortality (3 mo) (No.) (\%) & $207(26.5)$ & $11(16.2)$ & $13(20.6)$ & .120 & NA \\
\hline \multirow[t]{2}{*}{ sICH (No.) (\%) } & $42(5.5)$ & $1(1.5)$ & $2(3.3)$ & .380 & NA \\
\hline & $\begin{array}{l}\text { Control Group } \\
\quad(n=780)\end{array}$ & $\begin{array}{l}\text { WUS[mri] } \\
(n=47)\end{array}$ & $\begin{array}{l}\text { DUS[mri] } \\
(n=52)\end{array}$ & & \\
\hline \multicolumn{6}{|l|}{ B) MRI [mri] } \\
\hline mRS 0-2 (3 mo) (No.) (\%) & $299(38.3)$ & $24(51.1)$ & $20(38.5)$ & .216 & NA \\
\hline In-hospital mortality (No.) (\%) & $145(18.9)$ & $2(4.3)$ & $8(15.4)$ & .024 & $\begin{array}{l}\text { (A) } .009 \\
\text { (B) } .713 \\
\text { (C) } .204\end{array}$ \\
\hline All-cause mortality (3 mo) (No.) (\%) & $207(26.5)$ & $6(12.8)$ & $12(23.1)$ & .093 & NA \\
\hline \multirow[t]{2}{*}{ sICH (No.) (\%) } & $42(5.5)$ & $1(2.2)$ & $2(4.0)$ & .808 & NA \\
\hline & $\begin{array}{l}\text { Control [mri] } \\
(n=170)\end{array}$ & $\begin{array}{l}\text { WUS[mri] } \\
(n=47)\end{array}$ & $\begin{array}{l}\text { DUS[mri] } \\
(n=52)\end{array}$ & & \\
\hline \multicolumn{6}{|c|}{ C) MRI compared with selected controls [mri] } \\
\hline mRS 0-2 (3 mo) (No.) (\%) & $83(48.8)$ & $24(51.1)$ & $20(38.5)$ & .357 & NA \\
\hline In-hospital mortality (No.) (\%) & $19(11.5)$ & $2(4.3)$ & $8(15.4)$ & .211 & NA \\
\hline All-cause mortality (3 mo) (No.) (\%) & $34(20.0)$ & $6(12.8)$ & $12(23.1)$ & .385 & NA \\
\hline sICH (No.) (\%) & $5(3.0)$ & $1(2.2)$ & $2(4.0)$ & .875 & NA \\
\hline
\end{tabular}

Note:- $-\mathrm{I} \mathrm{CH}$ indicates symptomatic intracranial hemorrhage; NA, not applicable.

a $P$ value for group comparison.

b $P$ value for head-to-head comparison, calculated when the $P$ value for the group comparison was <.05: (A), control group vs WUS; (B), control group vs DUS; (C), WUS vs DUS. 


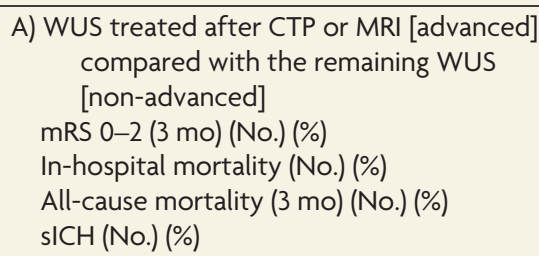

B) DUS treated after CTP and MRI [advanced] compared with the remaining DUS [non-advanced]

mRS 0-2 (3 mo) (No.) (\%)

In-hospital mortality (No.) (\%)

All-cause mortality (3 mo) (No.) (\%)

sICH (No.) (\%)

C) WUS treated after MRI [mri] compared with the remaining WUS [non-mri]

mRS 0-2 (3 mo) (No.) (\%)

In-hospital mortality (No.) (\%)

All-cause mortality (3 mo) (No.) (\%)

sICH (No.) (\%)

D) DUS treated after MRI [mri] compared with the remaining DUS [non-mri]

mRS 0-2 (3 mo) (No.) (\%)

In-hospital mortality (No.) (\%)

All-cause mortality (3 mo) (No.) (\%)

sICH (No.) (\%)

$\begin{array}{cc}32(47.1) & 14(23.3) \\ 5(7.5) & 11(18.3) \\ 11(16.2) & 18(30.0) \\ 1(1.5) & 2(3.4) \\ \text { DUS[advanced] }(n=63) & \text { Non-DUS[advanced] }(n=102)\end{array}$

$2.92(1.32-6.45), .006$

$0.36(0.11-1.12), .106$

$0.45(0.19-1.07), .090$

$0.43(0.04-4.95), .599$

Note:- - ICH indicates symptomatic intracranial hemorrhage.

likewise led to a significant increase in the frequency of good functional outcome in patients with WUS and DUS. Consecutive steps in patient selection ( 1 , all patients; 2 , patients with CTP or MR imaging; 3, patients with MR imaging; 4, patients with documented mismatch in CTP or MR imaging; 5, patients with documented mismatch in MR imaging) increased the frequency of good functional outcome in both WUS and DUS (WUS 1: 35.9\%; WUS 2: 47.1\%; WUS 3: 51.1\%; WUS 4: 51.9\%; WUS 5: 52.8\%; DUS 1: 27.3\%; DUS 2: 36.5\%; DUS 3: 38.5\%; DUS 4: 39.1\%; DUS 5: 43.2\%). Outcome in DUS still was reduced. However, with the application of advanced imaging techniques, the statistically significant difference disappeared.

Besides outcome, WUS and DUS also seem to differ in pathophysiologic characteristics. An increase in platelet aggregation as well as a blood pressure surge during awakening are said to be associated with WUS but not DUS. ${ }^{29,30}$ WUS might occur right before awakening and therefore be comparable with a stroke population with documented symptom onset. ${ }^{31}$ Indeed, it was shown that clinical and imaging characteristics in WUS and stroke eligible for intravenous thrombolysis seem to be comparable, whereas DUS - as in our cohort — tends to have a worse prognosis. ${ }^{13,32,33}$ We did not observe significant differences in baseline characteristics. Longer imaging-to-groin times in WUS and DUS can be explained by a higher percentage of MR imaging scans and might indicate a careful patient selection. An average 138 minutes in controls is attributed to many patients being secondarily transferred for mTE/aTE. ${ }^{10}$

This study has several limitations. First, due to the retrospective design, selection bias can be suspected because we do not know in which cases mTE or aTE was not considered. Also, a certain inconsistency in decision-making can be assumed. Second, the definition of WUS and DUS could lead to some overlap of groups. Some of the patients categorized as having DUS by the assessing neurologist (eg, patients arriving late in the evening) could be WUS instead. There was no common CTP protocol or quantitative mismatch measurement, which may reduce comparability. An imbalance in group size might introduce a power problem (especially in subgroup analysis).

\section{CONCLUSIONS}

Our data suggest that mTE/aTE in selected patients with WUS allows a good functional outcome comparable with that in patients treated within 6 hours of symptom onset. Patients with DUS seem to be inferior to controls regarding outcome and mortality rates. The application of advanced imaging modalities (MR imaging, CTP) significantly increases the frequency of good functional outcome in both WUS and DUS and seems to reduce mortality.

\section{ACKNOWLEDGMENTS}

We were supported by Hiltrud Niggemann in performing the statistical analysis. Casjupea Knispel, stroke and study nurse of the Neuroradiological Clinic, participated in data collection and conducted the follow-up interviews.

Disclosures: Marta Aguilar Pérez-UNRELATED: Consultancy: phenox, Comments: proctor and consultant. Hansjörg Bäzner-UNRELATED: Payment for Lectures In cluding Service on Speakers Bureaus: Bayer AG, Vital Pharma GmbH, Boehringer 
Ingelheim, Bristol-Myers Squibb, Daiichi Sankyo. Hans Henkes-UNRELATED: Board Membership: phenox, Comments: I am Speaker of the Board without payment; phenox compensates travel expenses; Consultancy: phenox, Comments: I am a consultant phenox and receive financial compensation for this effort; Patents (Planned, Pending or Issued): phenox, Medtronic, Comments: I am a coinventor of several intellectual property claims held by Medtronic and phenox; Stock/Stock Options: phenox, Comments: I am cofounder and shareholder of phenox; Travel/Accommodations/Meeting Expenses Unrelated to Activities Listed: phenox, Comments: I receive compensation for travel expenses for activities on behalf of phenox.

\section{REFERENCES}

1. Berkhemer OA, Fransen PS, Beumer D, et al. A randomized trial of intraarterial treatment for acute ischemic stroke. N Engl J Med 2015; 372:11-20 CrossRef Medline

2. Goyal M, Demchuk AM, Menon BK, et al; ESCAPE Trial Investigators. Randomized assessment of rapid endovascular treatment of ischemic stroke. N Engl J Med 2015;372:1019-30 CrossRef Medline

3. Saver JL, Goyal M, Bonafe A, et al; SWIFT PRIME Investigators. Stent-retriever thrombectomy after intravenous t-PA vs. t-PA alone in stroke. $N$ Engl J Med 2015;372:2285-95 CrossRef Medline

4. Campbell BC, Mitchell PJ, Kleinig TJ, et al; EXTEND-IA Investigators. Endovascular therapy for ischemic stroke with perfusion-imaging selection. $N$ Engl J Med 2015;372:1009-18 CrossRef Medline

5. Jovin TG, Chamorro A, Cobo E, et al; REVASCAT Trial Investigators. Thrombectomy within $\mathbf{8}$ hours after symptom onset in ischemic stroke. N Engl J Med 2015;372:2296-306 CrossRef Medline

6. Wahlgren N, Moreira T, Michel P, et al; ESO-KSU, ESO, ESMINT, ESNR and EAN. Mechanical thrombectomy in acute ischemic stroke: consensus statement by ESO-Karolinska Stroke Update 2014/2015, supported by ESO, ESMINT, ESNR and EAN. Int J Stroke 2016;11:134-47 CrossRef Medline

7. Mokin M, Kan P, Sivakanthan S, et al. Endovascular therapy of wake-up strokes in the modern era of stent retriever thrombectomy. J Neurointerv Surg 2016;8:240-43 CrossRef Medline

8. Qureshi AI, Miley JT, Chaudhry SA, et al. Safety and effectiveness of endovascular treatment after 6 hours of symptom onset in patients with anterior circulation ischemic stroke: a matched case control study. J Stroke Cerebrovasc Dis 2013;22:1076-81 CrossRef Medline

9. Kuntze Söderqvist $\AA$, Andersson T, Wahlgren N, et al. Mechanical thrombectomy in acute ischemic stroke: patients with wake-up stroke and the elderly may benefit as well. J Stroke Cerebrovasc Dis 2016;25:2276-83 CrossRef Medline

10. Bücke P, Pérez MA, Schmid E, et al. Endovascular thrombectomy in acute ischemic stroke: outcome in referred versus directly admitted patients. Clin Neuroradiol 2017 Jan 31. [Epub ahead of print] CrossRef Medline

11. Kim YJ, Kim BJ, Kwon SU, et al. Unclear-onset stroke: daytimeunwitnessed stroke vs. wake-up stroke. Int J Stroke 2016;11:212-20 CrossRef Medline

12. Wouters A, Lemmens $R$, Dupont $P$, et al. Wake-up stroke and stroke of unknown onset: a critical review. Front Neurol 2014;5:153 CrossRef Medline

13. Reid JM, Dai D, Cheripelli B, et al. Differences in wake-up and unknown onset stroke examined in a stroke registry. Int J Stroke 2015; 10:331-35 CrossRef Medline

14. Bouslama M, Haussen DC, Grossberg JA, et al. Computed tomographic perfusion selection and clinical outcomes after endovascular therapy in large vessel occlusion stroke. Stroke 2017;48:1271-77 CrossRef Medline

15. Campbell BC, Yassi N, Ma H, et al. Imaging selection in ischemic stroke: feasibility of automated CT-perfusion analysis. Int J Stroke 2015;10:51-54 CrossRef Medline

16. Thomalla G, Cheng B, Ebinger M, et al; VISTA Imaging Investigators. DWI-FLAIR mismatch for the identification of patients with acute ischaemic stroke within $4.5 \mathrm{~h}$ of symptom onset (PRE-FLAIR): a multicentre observational study. Lancet Neurol 2011;10:978-86 CrossRef Medline

17. Thomalla G, Boutitie F, Fiebach JB, et al; WAKE-UP Investigators Stroke with unknown time of symptom onset: baseline clinical and magnetic resonance imaging data of the first thousand patients in WAKE-UP (efficacy and safety of MRI-based thrombolysis in wake-up stroke: a randomized, doubleblind, placebo-controlled trial). Stroke 2017;48:770-73 CrossRef Medline

18. Turk A, Magarik JA, Chaudry I, et al. CT perfusion-guided patient selection for endovascular treatment of acute ischemic stroke is safe and effective. J Neurointerv Surg 2012;4:261-65 CrossRef Medline

19. Michel P, Ntaios G, Reichhart M, et al. Perfusion-CT guided intravenous thrombolysis in patients with unknown-onset stroke: a randomized, double-blind, placebo-controlled, pilot feasibility trial. Neuroradiology 2012;54:579-88 CrossRef Medline

20. Saver JL, Goyal M, Bonafe A, et al; SWIFT PRIME Investigators. Solitaire $^{\mathrm{TM}}$ with the Intention for Thrombectomy as Primary Endovascular Treatment for Acute Ischemic Stroke (SWIFT PRIME) trial: protocol for a randomized, controlled, multicenter study comparing the Solitaire revascularization device with IV tPA with IV tPA alone in acute ischemic stroke. Int J Stroke 2015;10:439-48 CrossRef Medline

21. Cho AH, Sohn SI, Han MK, et al. Safety and efficacy of MRI-based thrombolysis in unclear-onset stroke: a preliminary report. Cerebrovasc Dis 2008;25:572-79 CrossRef Medline

22. Schellinger PD, Thomalla G, Fiehler J, et al. MRI-based and CTbased thrombolytic therapy in acute stroke within and beyond established time windows: an analysis of 1210 patients. Stroke 2007; 38:2640-45 CrossRef Medline

23. Abou-Chebl A. Endovascular treatment of acute ischemic stroke may be safely performed with no time window limit in appropriately selected patients. Stroke 2010;41:1996-2000 CrossRef Medline

24. Natarajan SK, Snyder KV, Siddiqui AH, et al. Safety and effectiveness of endovascular therapy after 8 hours of acute ischemic stroke onset and wake-up strokes. Stroke 2009;40:3269-74 CrossRef Medline

25. Third European Stroke Organisation Conference. Prague, Czech Republic. May 16-18, 2017; https://eso-stroke.org/kategorie-1/datahighlights-opening-plenary-esoc-2017/. Accessed October 18, 2017

26. NeuroNews. DEFUSE 3 terminated early with high likelihood of benefit in the endovascular group. https://neuronewsinternational.com/ defuse-3-terminated-early-high-likelihood-benefit-endovasculargroup/. Accessed October 18, 2017

27. Jovin TG, Saver JL, Ribo M, et al. Diffusion-weighted imaging or computerized tomography perfusion assessment with clinical mismatch in the triage of wake up and late presenting strokes undergoing neurointervention with Trevo (DAWN) trial methods. Int J Stroke 2017;12:641-52 CrossRef Medline

28. Albers GW, Lansberg MG, Kemp S, et al. A multicenter randomized controlled trial of endovascular therapy following imaging evaluation for ischemic stroke (DEFUSE 3). Int J Stroke 2017;12:896-905 CrossRef Medline

29. Lundholm MD, Rooney M, Maas MB, et al. Wake-up stroke is associated with greater nocturnal mean arterial pressure variability. Stroke 2017;48:1668-70 CrossRef Medline

30. Kario K, Yano Y, Matsuo T, et al. Morning blood pressure surge, morning platelet aggregation, and silent cerebral infarction in older Japanese hypertensive patients. J Hypertens 2011;29:2433-39 CrossRef Medline

31. Rubin MN, Barrett KM. What to do with wake-up stroke. Neurohospitalist 2015;5:161-72 CrossRef Medline

32. Mackey J, Kleindorfer D, Sucharew H, et al. Population-based study of wake-up strokes. Neurology 2011;76:1662-67 CrossRef Medline

33. Costa R, Pinho J, Alves JN, et al. Wake-up stroke and stroke within the therapeutic window for thrombolysis have similar clinical severity, imaging characteristics, and outcome. J Stroke Cerebrovasc Dis 2016;25:511-14 CrossRef Medline 